\title{
Polypharmacy Among Home-Dwelling Older Adults: The Urgent Need for an Evidence-Based Medication Management Model
}

This article was published in the following Dove Press journal:

Patient Preference and Adherence

\author{
Filipa Pereira (1D) ${ }^{1,2}$ \\ Armin von Gunten ${ }^{3}$ \\ Joëlle Rosselet Amoussou (iD ${ }^{4}$ \\ Isabella De Giorgi Salamun (D) ${ }^{5}$ \\ Maria Manuela Martins (iD) 2,6 \\ Henk Verloo iD ${ }^{1,3}$ \\ 'School of Health Sciences, HES-SO \\ Valais-Wallis, Sion, Switzerland; ${ }^{2}$ Institute \\ of Biomedical Sciences Abel Salazar, \\ University of Porto, Porto, Portugal; \\ ${ }^{3}$ Service of Old Age Psychiatry, Lausanne \\ University Hospital, Lausanne, \\ Switzerland; ${ }^{4}$ Psychiatry Library, \\ Education and Research Department, \\ Lausanne University Hospital and \\ University of Lausanne, Lausanne, \\ Switzerland; ${ }^{5}$ Service of Pharmacy, \\ Lausanne University Hospital, Lausanne, \\ Switzerland; ${ }^{6} \mathrm{Higher}$ School of Nursing of \\ Porto, Porto, Portugal
}

Correspondence: Filipa Pereira

School of Health Sciences, HES-SO Valais-

Wallis, Chemin de l'Agasse 5, Sion $\mathrm{CH}$ -

1950, Switzerland

Tel +4I 786661700

$\mathrm{Fax}+4 I 276068400$

Email filipa.pereira@hevs.ch

\begin{abstract}
Ageing populations with multiple chronic conditions challenge low-, middle-, and high-income countries. Older adults frequently depend on complex medication regimens and polypharmacy, both of which can lead to potentially devastating and debilitating medication-related problems and to subsequent far-reaching public health, social, and economic effects. This perspectives article provides an overview of the current state of medication management, reflects on its relevance among polymedicated home-dwelling older adults living with multiple chronic conditions, and proposes patient-centered approaches for optimizing medication management and preventing medication-related problems.
\end{abstract}

Keywords: multiple chronic conditions, medication-related problems, caregivers, interprofessional collaboration, patient-centered care

\section{Ageing Populations with Multiple Chronic Conditions Challenge Low-, Middle-, and High-Income Countries}

Ageing populations represent one of the most significant current challenges to the longterm sustainability and efficiency of the world's healthcare and social services systems. ${ }^{1}$ Despite increases in life expectancy, older adults are not experiencing better health than previous generations. ${ }^{2}$ Worldwide, the prevalence of multimorbidity in older adults ranges from 55-98\% ${ }^{3}$ In Switzerland, 25.2\% of adults aged from 65-79 years old, and $41.3 \%$ of those aged 80 or more, live at home with multimorbidity. ${ }^{4}$ Three major operational definitions of multimorbidity co-exist in the literature: cooccurrence of at least two diseases in the same individual; cumulative indices considering both the number and severity of concurrent diseases; and the simultaneous presence of not only diseases but also their associated symptoms and physical and cognitive dysfunctions. ${ }^{3}$ To properly cover the heterogeneity and complexity of older adults' health statuses, this paper uses the term multiple chronic conditions to encompass all three definitions. ${ }^{5}$ Older adults living with multiple chronic conditions present a poorer quality of life, declines in functional ability and mobility, ${ }^{3}$ and shorter life expectancy, particularly those with cognitive impairment and/or cardiovascular disease. ${ }^{6}$ The concept of multiple chronic conditions is also associated with increased psychological distress and repeated and prolonged hospitalizations. ${ }^{3}$ Although the expanding number of patients with multiple chronic conditions is considered a public health concern, prevalence often remains unclear, especially given the absence of any 
consensual definition in ongoing epidemiological investigations. Nonetheless, regardless of the definition, multiple chronic health conditions among home-dwelling older adults have been strongly associated with polypharmacy and medication-related problems (MRPs) in multiple observational and epidemiological studies. ${ }^{7,8}$

\section{Polypharmacy and Medication-Related Problems}

Older people with multiple chronic conditions - particularly those with cognitive impairment and/or psychiatric disorders-frequently depend on complex medication regimens. A recent Swiss study reported that more than $80 \%$ of home-dwelling older adults took at least one drug daily, with some taking up to $17 .{ }^{9}$ Indeed, $27 \%$ had a daily intake of five or more drugs, with numbers increasing with age: $18 \%$ of those aged $69-74$, rising to $38 \%$ of those aged 85 or more. However, nearly $50 \%$ of older adults took at least one medication that was not medically required. ${ }^{9}$

Although the use of multiple medicines or polypharmacy may be clinically appropriate in many cases, it is imperative to identify those older adults with inappropriate polypharmacy prescriptions that may put them at a greater risk of MRPs and adverse health outcomes. ${ }^{10,11}$ To distinguish between appropriate and inappropriate polypharmacy, Masnoon et al (2017) conducted a systematic literature review to explore the different definitions of polypharmacy. ${ }^{12}$ They found 138 definitions of polypharmacy and associated terms. Although the most commonly used definition of polypharmacy is taking five or more medicines, ${ }^{12}$ the variety of definitions could confuse clinicians in practice and make it difficult to assess the safety and appropriateness of a medication therapy in clinical settings. There is an urgent need for an international consensus definition of polypharmacy, including how to assess inappropriate polypharmacy, in order to optimize medication management and clinical follow-up and to enable precisely comparable criteria in research.

Regardless of polypharmacy's definition, polymedicated older adults are more susceptible to MRPs, including adverse drug reactions, medication errors, and non-adherence, which often result in emergency department visits and hospitalizations. ${ }^{10,11}$ Up to $25 \%$ of emergency department visits by home-dwelling older adults with multiple chronic conditions are attributable to an MRP. ${ }^{13}$ Nonetheless, $60 \%$ of MRPs in older patients visiting emergency departments with non-specific signs and symptoms (such as weakness) may go undiagnosed as such, whereas $83 \%$ of those MRPs may be accountable for acute morbidity. ${ }^{13}$ MRPs also frequently result in readmission: in one study following older patients for six months after hospital discharge, they were the most frequent cause. ${ }^{14}$ Evidence suggests that the risk of an MRP increases not only with age and the number of comorbidities but also with the number of medications prescribed and with certain classes of drugs, such as medicines for cardiovascular diseases and diabetes. ${ }^{11,13}$ Thus, MRPs can lead to a degradation in the patient's clinical condition, physical and cognitive decline, an exacerbation of chronic medical conditions, and avoidable health costs. ${ }^{13,15}$ MRPs can be devastating and debilitating for older people, and they can have far-reaching public health, social, and economic impacts.

A possible explanation for high numbers of MRPs is that most clinical guidelines and intervention care models were designed using short-term randomized controlled trials involving single health conditions. This contrasts with the current reality of the multiple, chronic, and often interacting health conditions affecting older people. Trying to implement multiple clinical guidelines for a single disease among older adults with multiple chronic conditions may result in contradictory and potentially harmful recommendations. ${ }^{16}$ The pathophysiological processes, clinical features, and interactions of age-related conditions must be disentangled, as much as possible, in order to personalize medication and its management and to realign older adults, caregivers, and healthcare systems so as to prevent MRPs.

Due to the high prevalence of polypharmacy and MRPs, together with their impact on older adults' quality of life and public healthcare expenditure, medication management has emerged as a priority in clinical settings. Its necessity among older adults has also become the focus of considerable research interest and media attention over the last decade (Figure 1). However, the mechanisms behind poor medication management are not well defined.

The present paper provides a timely addition to the burgeoning body of evidence offering new perspectives on our understanding of medication management-well beyond the act of medical prescription itself - among polymedicated home-dwelling older adults with multiple chronic conditions.

\section{Optimizing Medication Use Among Older Adults with Multiple Chronic Conditions}

MRPs are a reflection of the complexity of dealing with polypharmacy and age-related multiple chronic conditions; 


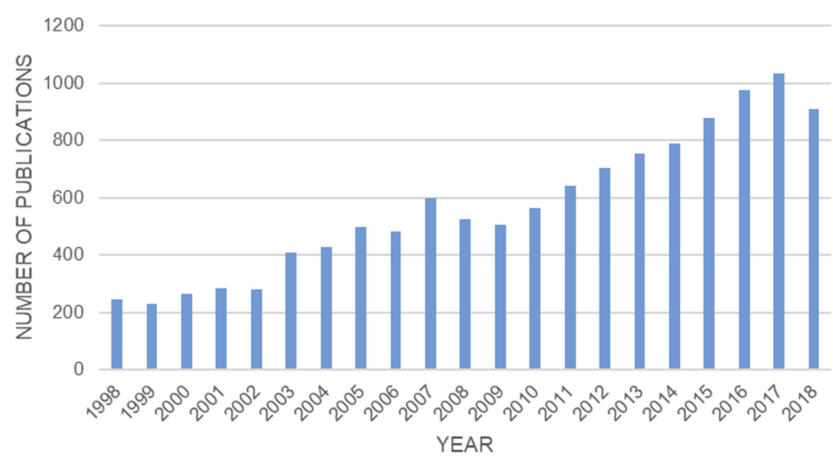

Figure I Papers referenced in Pubmed over the last 20 years on medication management among older adults.

Notes: Graph obtained with the following research equation: ("Aged"[Mesh] OR “Geriatrics”[Mesh] OR “Geriatric Psychiatry”[Mesh] OR “Geriatric Nursing”[Mesh] OR "Geriatric Assessment"[Mesh] OR "Health Services for the Aged"[Mesh]) AND ("Medication Therapy Management"[Mesh] OR "Drug Monitoring"[Mesh] OR "Product Surveillance, Postmarketing"'[Mesh] OR “Drug Utilization Review"[Mesh] OR “Deprescriptions"[Mesh] OR "Potentially Inappropriate Medication List"[Mesh] OR “Medication Reconciliation"[Mesh] OR “Medication Systems"[Mesh] OR “Medication Errors/prevention and control"'Mesh] OR "Prescription Drug Overuse/prevention and control"[Mesh] OR ((“Drug Therapy"[Mesh] OR “Drug Prescriptions”[Mesh]) AND ("Self-Care"[Mesh] OR "Patient Education as Topic"[Mesh]))) AND ("I998/0I/ OI”[PDAT]: “20I8/I2/3I”[PDAT])

they are causally underpinned by interacting and often unclear pathophysiological, pharmacodynamic, and pharmacokinetic processes. Furthermore, the signs of a normal ageing process are not always easy to tell apart from the potential pathophysiological deviations induced by underlying chronic conditions. ${ }^{17,18}$ The occurrence of MRPs is strongly affected by a broad range of factors and determinants, which are not confined to single biological systems or human health domains. ${ }^{17}$ Environmental and social factors also substantially influence MRPs. ${ }^{11}$

MRPs are nonetheless preventable with appropriate, well-coordinated primary care. ${ }^{11,13,19}$ For example, $20-30 \%$ of avoidable older adult readmissions have been directly related to non-adherence. ${ }^{20}$ Some of the current evidence-based strategies for medication safety and the prevention of MRPs include medication reconciliation, systematic review of prescribed medications, deprescribing, and electronic medication management systems. ${ }^{21,22}$

Medication reconciliation is a well-documented good practice corresponding to the process of creating and updating a single list of an older adult's medication ${ }^{23}$ this ensures a systematic, comprehensive review of all the patient's current medicines. Prior research has shown that discharge letters received by primary care professionals are frequently inaccurate and lack key information. ${ }^{24}$ Regular medication reconciliation reduces medication errors by consistent communication across transitions of care, including changes in the clinical setting, medical practitioner, or level of care. ${ }^{25}$
Regularly and systematically reviewing prescribed medications is a straightforward, effective means of reducing inappropriate prescribing and, therefore, a preventive strategy for avoiding MRPs. Inappropriate prescribing includes potentially inappropriate medications and potential prescribing omissions. Existing screening tools - such as the STOPP/START criteria (Screening Tool of Older Persons' Prescriptions/Screening Tool to Alert to Right Treatment) — recognize the dual nature of inappropriate prescribing by including a list of potentially inappropriate medications (STOPP criteria) and potential prescribing omissions (START criteria). ${ }^{26}$ Complementary to this, the American Geriatrics Society Beers Criteria is a list of potentially inappropriate medications that it is preferable for older adults to avoid in most situations or particular health conditions. ${ }^{27}$

Deprescribing attempts to balance the potential benefits and harms of tapering or ceasing inappropriate medication with the aim of managing polypharmacy and improving outcomes. ${ }^{28}$ Deprescribing is particularly relevant among frail older adults with multiple chronic conditions, as they face high risks of MRPs, hospitalization, and early death. ${ }^{21}$

Electronic medication management systems are recent digital developments covering prescriptions, administration, pharmacy reviews, medication administration using barcodes, and all the electronic devices devoted to medication management processes. $^{22}$ Electronic medication management systems contribute to reducing medication errors and enhancing interprofessional collaboration and patient safety by using red flag strategies. ${ }^{29,30}$ In recent years, smartphone applications for optimizing medication use have also emerged. However, older adults, who can experience the greatest benefits from more electronic support to improve their medication use, are also the least accustomed to using them. ${ }^{21}$

\section{Integrating Older Adults' Preferences into Medication Management}

Preventability and an understanding of risk factors are crucial to co-constructing interventions to minimize MRPs. ${ }^{11,19}$ However, research about MRPs and medication management currently focuses on healthcare professionals' perspectives, to which the perspectives and experiences of patients and informal caregivers are often secondary. Research into medication management has evolved with little consideration of the perspectives and preferences of older adults themselves. Further studies- 
using qualitative or mixed research designs-will be essential to identify the logic which home-dwelling older adults with multiple chronic conditions apply to the management of their daily medication and how they integrate it into the rhythm of their daily lives and home environments. ${ }^{14,19}$ Shared decision-making must be promoted, notably via operational tools providing information on the benefits and risks of medicines in a format which older adults can embrace more easily. ${ }^{31}$ Even though empowering patients to participate in their medication management has beneficial effects - particularly in medication adherence ${ }^{32}$ - the concept of older adult empowerment and self-management of complex medication regimens, along with their impact on MRPs, has been poorly investigated. Quasi-experimental studies and randomized controlled trials will be essential for any adequate exploration of the effectiveness of innovative interventions aiming to empower older adults' medication management, improve their competences, and enhance shared decisionmaking with healthcare professionals.

\section{The Roles and Accountability of Healthcare Professionals}

The complexity of care required by home-dwelling older adults with multiple chronic conditions leads them to be significant users of healthcare services and to consult many different healthcare professionals. ${ }^{33}$ Medication management among this population consequently requires interprofessional collaboration across different healthcare and social services providers and organizations. ${ }^{16}$ Besides prescribers, usually general practitioners and different specialist physicians, pharmacists, nurses, and other allied health professionals may be involved in and accountable for medication management. ${ }^{16}$ In Australia, collaborative home medicines reviews (involving a general practitioner and a pharmacist) have demonstrated their effectiveness in detecting, preventing, and resolving MRPs among home-dwelling older adults with multiple chronic conditions. ${ }^{16}$ Furthermore, adherence to prescribed medication can also be improved by pharmacist- and nurse-led interventions. ${ }^{34-37}$ However, the higher the number of healthcare professionals consulted by homedwelling older adults with multiple chronic conditions, the greater the chance that care may be fragmented and uncoordinated. ${ }^{16}$ This can be explained by the different treatment preferences of different healthcare professionals. Home-dwelling older adults with multiple chronic conditions often fail to receive the efficient, effective, and coordinated care that they could gain so much from. ${ }^{38,39}$ Failure to coordinate care for home-dwelling older adults with multiple chronic conditions undeniably increases the risk of MRPs. ${ }^{16}$ Those who consult three or more healthcare professionals report receiving conflicting advice, which makes it difficult for them to know which guidance they should follow. Inadequate explanations about medication result in omissions and incorrect dosages, but also in anxiety and confusion in older adults. ${ }^{40}$ Healthcare professionals should feel accountable for optimizing medication management among home-dwelling older adults, particularly during their transitions home from acute care settings. Implementing effective primary care management should be a priority among homedwelling older adults with multiple chronic conditions in order to prevent adverse health outcomes and to promote autonomy in their daily lives. Older adults at a high risk of MRPs should systematically be assigned a primary care manager whose aim is to meet their needs with regards to prevention and chronic conditions. By using planned interactions and ensuring appropriate follow-up, primary care managers can contribute significantly to the prevention of hospital admissions, rehospitalizations, institutionalization in nursing homes, and early death. ${ }^{41,42}$

\section{The Role of Informal Caregivers}

In addition to healthcare professionals' contributions to medication management, informal caregivers help to ensure safe, appropriate medication use at home by older adults with multiple chronic conditions, notably among those who may also have cognitive impairment. ${ }^{43-45}$ Although the role of informal caregivers in medication management is very relevant, various constraints have been reported regarding the time required, anxiety about making mistakes, and the uncollaborative behavior of older adults. ${ }^{46}$ They also face difficulties maintaining continuous supplies of medicines, supporting administrative work, making clinical decisions, and handling conflicts or disagreements with the older adult, ${ }^{46}$ or even with healthcare professionals in regards to ineffective medicinal practices. ${ }^{43,46}$ Although several studies have furthered understanding about the daily challenges faced by informal caregivers managing medication for older adults, there has been less insight into any educational or training interventions aimed at improving caregivers' medication management competences. More studies are required to explore how to efficiently support informal caregivers in their roles as medication managers. Psychoeducation, digital applications, or specialized counselling services 
provided by pharmacists or advanced practice nurses should also be considered. ${ }^{44,45,47}$ Cooperating with informal caregivers and integrating their experiences of shared decision-making should be one of the tasks assigned to primary healthcare professionals. To make this a reality, they could receive backing from their hierarchies and perhaps even financial incentives to support informal caregivers in the optimization of medication management. More research will be needed to analyze the effectiveness of such incentives.

\section{Ways to Bridge the Gap}

Optimal medication management is one of the basic preconditions for home-dwelling older adults with multiple chronic conditions to be able to remain at home and preserve their quality of life., ${ }^{7,48}$ Improving medication management for them not only requires regular monitoring of MRPs and reviewing of prescriptions to eliminate unnecessary medication but also coordinated care by different healthcare and social services providers. ${ }^{49}$ This calls for an integrated, multistakeholder model to optimize medication management among home-dwelling older adults with multiple chronic conditions. Such a medication management model should be rigorously structured using a care model process embracing development, implementation, and sustainability milestones. ${ }^{50}$ It should also consider the quadruple aim of enhancing the patient's experience, improving population health, reducing costs, and improving healthcare professionals' working lives. $^{51}$ Indeed, both these frameworks underpin the ongoing mixed-methods research by Pereira et al, which brings together retrospective and prospective findings to promote medication management and prevent MRPs. ${ }^{52}$ Such a model should be able to more adequately capture the biological, clinical, psychosocial, and pharmacological complexities of multiple chronic conditions and polypharmacy. A robust, integrated, multi-stakeholder model that embeds care in the context of where and how older adults with multiple chronic conditions live needs to be developed to prevent the onset and/or progression of MRPs.

\section{Disclosure}

This work was supported by the Swiss National Science Foundation's National Research Programme 74 [407440_ 183434/1]. Prof. Dr. Armin von Gunten reports grants from the National Research Foundation, during the conduct of the study. The authors report no other conflicts of interest in this work.

\section{References}

1. European Innovation Partnership on Active and Healthy Ageing. ACTION PLAN on 'Innovation for Age-friendly buildings, cities \& environments'. Brussels: European Commission; 2012.

2. World Health Organization. Global Strategy and Action Plan on Ageing and Health. Geneva: World Health Organization;2017. 97892-4-151350-0.

3. Marengoni A, Angleman S, Melis R, et al. Aging with multimorbidity: a systematic review of the literature. Ageing Res Rev. 2011;10:430-439. doi:10.1016/j.arr.2011.03.003

4. Bachmann N, Burla L, Kohler D, et al. La santé en Suisse-Le point sur les maladies chroniques: rapport national sur la santé. Retrieved from Berne: \& older people's experiences of medicine changes on leaving hospital. Res Social Adm Pharm. 2015;10:791-800.

5. Valderas JM, Starfield B, Sibbald B, Salisbury C, Rloand M. Defining comorbidity: implications for understanding health and health services. Ann Fam Med. 2009;7:357-363. doi:10.1370/afm.983

6. Caughey GE, Ramsay EN, Vitry AI, et al. Comorbid chronic diseases, discordant impact on mortality in older people: a 14-year longitudinal population study. J Epidemiol Community Health. 2010;64:1036-1042. doi:10.1136/jech.2009.088260

7. Maher RL, Hanlon J, Hajjar ER. Clinical consequences of polypharmacy in elderly. Expert Opin Drug Saf. 2014;13:57-65. doi:10.1517/ 14740338.2013.827660

8. Díez-Manglano J, Giménez-López M, Garcés-Horna V, et al. Excessive polypharmacy and survival in polypathological patients. Eur J Clin Pharmacol. 2015;71:733-739. doi:10.1007/s00228-015$1837-8$

9. Renard D, Fustinoni S, Seematter-Bagnoud L, Santos-Eggimann B. Médicaments chez les seniors vaudois à domicile : nombre et composition [Medicines for senior citizens of Vaud at home: number and composition]. Lausanne: Centre d'Observation et d'Analyse du Vieillissement; 2015. French.

10. Monégat M, Sermet C. La polymédication définitions, mesures et enjeux: revue de la littérature et tests de mesure [Polymedication definitions, measures and issues: literature review and measurement tests. Health economics issues]. Questions d'économie de la santé. 2014;204. French.

11. Al Hamid A, Ghaleb M, Aljadhey H, Aslanpour Z. A systematic review of hospitalization resulting from medicine-related problems in adult patients. Br J Clin Pharmacol. 2014;78:202-217. doi:10.1111/ bcp.2014.78.issue-2

12. Masnoon N, Shakib S, Kalisch-Ellett L, Caughey GE. What is polypharmacy? A systematic review of definitions. BMC Geriatr. 2017;17:1-10. doi:10.1186/s12877-017-0621-2

13. Nickel CH, Ruedinger JM, Messmer AS, et al. Drug - related emergency department visits by elderly patients presenting with non-specific complaints. Scand J Trauma Resusc Emerg Med. 2013;21:15. doi:10.1186/1757-7241-21-15

14. Bonnet-Zamponi D, D'Arailh L, Konrat C, et al. Drug-related readmissions to medical units of older adults discharged from acute geriatric units: results of the optimization of medication in AGEd multicenter randomized controlled trial. $J$ Am Geriatr Soc. 2013;61:113-121. doi:10.1111/jgs.2013.61.issue-1

15. Fallis BA, Dhalla IA, Klemensberg J, Bell CM. Primary medication non-adherence after discharge from a general internal medicine service. PLoS One. 2013;8(5):e61735. doi:10.1371/journal.pone.0061735

16. Gilbert A, Roughead L, McDermott R, et al. Multiple chronic health conditions in older people: implications for health policy planning, practitioners and patients; 2013. Available from: https://www.unisa. edu.au/siteassets/episerver-6-files/global/health/sansom/documents/ qumprc/multiple-chronic-health-conditions.pdf. Accessed November 29, 2019. 
17. Clegg A, Young J, Iliffe S, Rikkert MO, Rockwood K. Frailty in elderly people. Lancet. 2013;381:752-762. doi:10.1016/S01406736(12)62167-9

18. Morley JE, Vellas B, van Kan GA, et al. Frailty consensus: a call to action. J Am Med Dir Assoc. 2013;14(6):392-397. doi:10.1016/j. jamda.2013.03.022

19. Pellegrin KL, Lee E, Uyeno R, Ayson C, Goo R. Potentially preventable medication-related hospitalizations: a clinical pharmacist approach to assessment, categorization, and quality improvement. J Am Pharm Assoc. 2017;57:711-716. doi:10.1016/j.japh.2017.06.019

20. Tang VL, Halm EA, Fine MJ, Johnson CS, Anzueto A, Mortensen EM. Predictors of rehospitalization after admission for pneumonia in the veterans affairs healthcare system. J Hosp Med. 2014;9:379-383. doi:10.1002/jhm.v9.6

21. Molokhia M, Majeed A. Current and future perspectives on the management of polypharmacy. BMC Fam Pract. 2017;18:1-9. doi:10.1186/s12875-017-0642-0

22. Pearce R, Whyte I. Electronic medication management: is it a silver bullet? Aust Prescr. 2018;41(2):32-33. doi:10.18773/austprescr.2018.012

23. Almanasreh E, Moles R, Chen TF. The medication reconciliation process and classification of discrepancies: a systematic review. $\mathrm{Br}$ J Clin Pharmacol. 2016;82(3):645-658. doi:10.1111/bcp.v82.3

24. Mekonnen AB, McLachlan AJ, Brien JA. Effectiveness of pharmacist-led medication reconciliation programmes on clinical outcomes at hospital transitions: a systematic review and meta-analysis. BMJ Open. 2016;6(2):e010003. doi:10.1136/bmjopen-2015-010003

25. IHI. How-To Guide: Prevent Adverse Drug Events by Implementing Medication Reconciliation. Cambridge, MA: Institute for Healthcare Improvement; 2011.

26. O’Mahony D, O’Sullivan D, Byrne S, O'Connor MN, Ryan C, Gallagher P. STOPP/START criteria for potentially inappropriate prescribing in older people: version 2. Age Ageing. 2015;44 (2):213-218. doi:10.1093/ageing/afu145

27. Fick DM, Semla TP, Steinman M, et al. American geriatrics society 2019 updated ags beers criteria(R) for potentially inappropriate medication use in older adults. J Am Geriatr Soc. 2019;67(4):674-694.

28. Page AT, Potter K, Clifford R, Etherton-Beer C. Deprescribing in older people. Maturitas. 2016;91:115-134. doi:10.1016/j.maturitas.2016. 06.006

29. Kallio S, Kumpusalo-Vauhkonen A, Järvensivu T, Mäntylä A, Pohjanoksa-Mäntylä M, Airaksinen M. Towards interprofessional networking in medication management of the aged: current challenges and potential solutions in Finland. Scand J Prim Health Care. 2016;34:368-376. doi:10.1080/02813432.2016.1249055

30. Shah K, Lo C, Babich M, Tsao NW, Bansback NJ. Bar code medication administration technology: a systematic review of impact on patient safety when used with computerized prescriber order entry and automated dispensing devices. Can J Hosp Pharm. 2016;69 (5):394-402. doi:10.4212/cjhp.v69i5.1594

31. Elwyn G, Frosch D, Thomson R, et al. Shared decision making: a model for clinical practice. J Gen Intern Med. 2012;27:1361-1367.

32. Náfrádi L, Nakamoto K, Schulz PJ. Is patient empowerment the key to promote adherence? A systematic review of the relationship between self-efficacy, health locus of control and medication adherence. PLoS One. 2017;12:10. doi:10.1371/journal.pone.0186458

33. Roughead EE, Vitry AI, Caughey GE, Gilbert AL. Multimorbidity, care complexity and prescribing for the elderly. Aging Health. 2011;7:695-705. doi:10.2217/ahe.11.64

34. Mehuys E, Dupond L, Petrovic M, et al. Medication management among home-dwelling older patients with chronic diseases: possible roles for community pharmacists. $J$ Nutr Health Aging. 2012;16:721-726. doi:10.1007/s12603-012-0028-x
35. Willis JS, Hoy RH, Jenkins WD. In-home medication reviews: a novel approach to improving patient care through coordination of care. J Community Health. 2011;36:1027-1031. doi:10.1007/s10900-0119405-3

36. Verloo H, Chiolero A, Kiszio B, Kampel T, Santschi V. Nurse interventions to improve medication adherence among discharged older adults: a systematic review. Age Ageing. 2017;46:747-754. doi:10.1093/ageing/afx076

37. Hannou S, Voirol P, Pannatier A, et al. Pharmacist intervention acceptance for the reduction of potentially inappropriate drug prescribing in acute psychiatry. Int J Clin Pharm. 2017;39:1228-1236. doi:10.1007/s11096-017-0513-8

38. Salisbury C, Salisbury C, Johnson L, et al. Epidemiology and impact of multimorbidity in primary care: a retrospective cohort study. $\mathrm{Br}$ J Gen Pract. 2011. doi:10.3399/bjgp11X548929

39. Boyd CM, Fortin M. Future of multimorbidity research: how should understanding of multimorbidity inform health system design? Public Health Rev. 2010;32(2):451.

40. Knight DA, Thompson D, Mathie E, Dickinson A. Seamless care? Just a list would have helped!'Older people and their carer's experiences of support with medication on discharge home from hospital. Health Expectations. 2013;16:277-291. doi:10.1111/hex.2013.16.issue-3

41. Parsons M, Senior H, Kerse N, et al. Should care managers for older adults be located in primary care? A randomized controlled trial. J Am Geriatr Soc. 2012;60(1):86-92. doi:10.1111/jgs.2012.60.issue-1

42. Available from: $<$ Chapter 38 medication reconciliation.pdf $>$. Accessed November 29, 2019.

43. O'Quin KE, Semalulu T, Orom H. Elder and caregiver solutions to improve medication adherence. Health Educ Res. 2015;30:323-335. doi:10.1093/her/cyv009

44. Gillespie R, Mullan J, Harrison L. Managing medications: the role of informal caregivers of older adults and people living with dementia. A review of the literature. J Clin Nurs. 2014;23:3296-3308. doi:10.1111/jocn.2014.23.issue-23pt24

45. Look KA, Stone JA. Medication management activities performed by informal caregivers of older adults. Res Social Adm Pharm. 2017.

46. Reinhard SC, Levine C, Samis S. Home alone: family caregivers providing complex chronic care. BMJ. 2012:41.

47. Pohontsch NJ, Loffler A, Luck T, et al. Informal caregivers' perspectives on health of and (potentially inappropriate) medication for (relatively) independent oldest-old people - a qualitative interview study. BMC Geriatr. 2018;18(1):169. doi:10.1186/s12877-018-0849-5

48. Williams GC, Patrick H, Niemiec CP, et al. Reducing the health risks of diabetes. Diabetes Educ. 2009;35:484-492. doi:10.1177/ 0145721709333856

49. Höpflinger F, Bayer-Oglesby L, Zumbrunn A. La dépendance des personnes âgées et les soins de longue durée. Cahier de l'Observatoire suisse de la santé. 2011;135. Höpflinger F, BayerOglesby L, Zumbrunn A. La dépendance des personnes âgées et les soins de longue durée [Elderly dependency and long-term care]. Bern: Observatoire Suisse de la Santé; 2011. French.

50. ACI. Understanding the Process to Develop a Model of Care: An ACI Framework. Chatswood: Agency for Clinical Innovation; 2013.

51. Bodenheimer T, Sinsky C. From triple to quadruple aim: care of the patient requires care of the provider. Ann Fam Med. 2014;12 (6):573-576. doi:10.1370/afm.1713

52. Pereira F, Roux P, Santiago-Delefosse M, et al. Optimising medication management for polymedicated home-dwelling older adults with multiple chronic conditions: a mixed-methods study protocol. BMJ Open. 2019;9(10):e030030. doi:10.1136/bmjopen-2019-030030 


\section{Publish your work in this journal}

Patient Preference and Adherence is an international, peer-reviewed, open access journal that focusing on the growing importance of patient preference and adherence throughout the therapeutic continuum. Patient satisfaction, acceptability, quality of life, compliance, persistence and their role in developing new therapeutic modalities and compounds to optimize clinical outcomes for existing disease

states are major areas of interest for the journal. This journal has been accepted for indexing on PubMed Central. The manuscript management system is completely online and includes a very quick and fair peer-review system, which is all easy to use. Visit http:// www.dovepress.com/testimonials.php to read real quotes from published authors.

Submit your manuscript here: https://www.dovepress.com/patient-preference-and-adherence-journal 